ESTUDOS RBE?

\title{
Discussão em torno da noção de acompanhamento de jovens adultos na educação superior
}

Regina Maria Caruccio Martins

\section{Resumo}

Propõe uma discussão em torno da noção de acompanhamento de jovens adultos na educação superior, no quadro de um projeto profissional, visando chegar a uma definição da noção e ao estado atual da questão. Apresenta, inicialmente, políticas europeias sobre a educação ao longo da vida, como medidas permitindo o desenvolvimento desta noção, e um questionamento originado na prática de acompanhamento do projeto profissional do aluno universitário. Numa etapa posterior, mostra como vem sendo construída esta noção na formação de adultos nesta última década. Na busca da definição do perfil do profissional de acompanhamento, do público, do contexto, dos objetivos e do tipo de intervenção, estabelece relações com a formação e o projeto profissional. Numa última etapa, chega às pesquisas francesas mais recentes na tentativa de definir esta atividade no referido contexto.

Palavras-chave: acompanhamento; formação de adultos; formação profissional. 


\section{Abstract \\ Discussion about the concept of guidance and supervision to young adults in the higher education}

It proposes a discussion about the concept of accompaniment provided to young adults in the higher education within the framework of a professional project. It aims to reach a definition of such a notion as well as take stock of the current state of the matter. Initially it provides an overview of the European life learning policies as tools encompassing such a concept, grounded on an assessment made from the perspective of our own practice gained while overseeing university students through their professional projects. At a later stage, it demonstrates how this concept of adult learning has been developed throughout the last decade. In the quest for a definition of the profile of the faculty project supervisor in charge of the accompaniment, the targeted audience, the context, the goals and type of intervention, seeks to establish how it interplays with learning and the professional project. At last, it takes a look at the most recent french research aiming to define the concept in question within said context.

Keywords: accompaniment; adult learning; professional education.

\section{Introdução}

A necessidade de desenvolver a questão epistemológica apresentou-se na nossa prática desde a primeira vez que abordamos o acompanhamento do projeto do estudante em situação de integrar o ensino superior. ${ }^{1}$ Entrávamos em conflito por causa dos diferentes papéis que deveríamos desempenhar na formação realizada. Pela primeira vez, estávamos diante das funções de formação e orientação de um público jovem adulto, acompanhando a elaboração de um projeto de estudos superiores com escolha profissional ao seu término.

Nossa atividade de formação ${ }^{2}$ tinha por objetivo a transmissão de um conteúdo teórico sobre as diferentes noções de projeto. Numa perspectiva antropológica (Boutinet, 1990), provocávamos uma reflexão da parte do estudante sobre possíveis projetos de vida. Colocando-se a questão inicial "por que entrar em projeto?", iniciava-se todo um trabalho de reflexão sobre as escolhas ${ }^{3}$ pessoais. Consideravam-se, também, os diferentes setores onde poderiam trabalhar futuramente (empresa, escola primária, ensino médio, ensino universitário, saúde, comércio, indústria, etc.), o tipo de atividade preferida (externa - ao ar livre; interna - em escritório ou em casa), o tipo de público com o qual trabalhariam (criança, jovem, adulto, profissionais confirmados, entre outros), etc. Fazendo uso da tipologia de Holland (1997) - realista, investigador, artístico, social, empreendedor e convencional - para estudo da personalidade do estudante por meio de um programa informatizado no Centro de Documentação e Informação (CDI) da Universidade, utilizávamos, também, exercícios para reproduzir a vida presente, passada e até futura (linha da vida, colagem). O objetivo era
${ }^{1}$ Os dois primeiros anos universitários do Diploma de Estudos Universitários Gerais (Deug) deixaram de existir com a reforma Attali, que instituiu o primeiro diploma a partir do $3^{\circ}$ ano universitário (nível Licence), o Master após 5 anos de estudos e o Doctorat com 8 anos ( $\mathrm{L}=3$; $\mathrm{M}=\mathrm{L}+2 ; \mathrm{D}=\mathrm{M}+3)$. Referimo-nos à nossa experiência na Universidade da Sorbonne - Paris III, de 1997 a 2001, intervindo sobre o Projeto Pessoal e Profissional. Este mesmo terreno serviu para fornecer os dados empíricos que foram explorados para a realização de nossa tese de doutorado, em que abordamos a questão ética para se avaliar o projeto (cf. Martins, 2010).

2 Trabalhávamos com estudantes inscritos no primeiro ano universitário do Deug que cursavam línguas estrangeiras nos diferentes departamentos da Universidade da Sorbonne - Paris III, onde desempenhamos paralelamente a função de Leitora de Português, de 1996 a 2005.

3 "Educação para a escolha", como se intitulava esta formação, na mesma época, na Universidade da Sorbonne - Paris IV, projeto retomado pelo ministro Fillon em 2005, expandido a todas as universidades. 
ajudar a pessoa a melhor se conhecer e se representar, acompanhando-a nesta descoberta pessoal, sem realizar nenhuma análise dos resultados obtidos em testes psicossociológicos, e permitindo-lhe concluir e constatar seu funcionamento, seus gostos e preferências, suas aspirações e projetos.

\section{A prática de acompanhamento do projeto}

Estudos realizados por Fond-Harmant (1995, 1996), Kaddouri (1996, 2001), Dubar (1998) e Bourgeois $(2000,2004)$ servem de referência a esta prática. Esses autores demonstraram que o projeto de um público jovem e adulto desejando integrar os estudos universitários depende, para realizar-se, de vários fatores: questões identitárias, histórias de vida, trajetórias sociais e projetos profissionais. A decisão de um casamento, a constituição de uma família, o nascimento de filhos (antes, durante ou depois dos estudos) são fatores também relevantes para jovens e adultos integrarem ou darem continuidade a uma formação universitária.

No caso da formação continuada transcorrendo paralelamente à atividade profissional, como na formação a distância, ${ }^{4}$ certas situações de vida podem atrapalhar o projeto de estudos, como doença ou morte de um ente querido (companheiro, pais, filhos), a separação ou o divórcio. Podem, ao mesmo tempo, representar um fator de motivação para o retorno aos estudos universitários (Fond-Harmant, 1996) ou uma tábua de salvação, permitindo à pessoa estruturar-se psicologicamente ou contribuindo para sua reconstrução identitária, sobretudo profissional (reconversão, reorientação profissional).

A escolha de cursos de curta ou longa duração determina a continuidade ou a ruptura dos estudos universitários. Pode ocorrer uma mudança de orientação nos estudos, durante a formação superior, para outro curso (de tipo técnico, por exemplo) que exija menos tempo de duração, como observado nos casos de elaboração do projeto em formação inicial de uma língua estrangeira. A necessidade da orientação profissional depende não somente do fator idade, mas também da escolha da disciplina universitária e da constituição de um currículo adaptado, dado que tais fatores podem determinar a escolha da carreira em final de formação. Nos casos presenciados em formação linguística, os estudantes podem dirigir-se a diferentes carreiras, como professor, tradutor-intérprete, jornalista, agente de turismo, etc., exigindo muita reflexão para definir uma escolha

4 Durante nossas atividades de Assistente Temporário de Ensino e Pesquisa (ATER) na Universidade da Franche-Comté em 2007-2008, realizamos uma pesquisa junto ao público inscrito na plataforma Moodle do Departamento de Educação e no curso de Educação e Promoção da Saúde para conhecer suas motivações de cursarem a formação enquanto profissionais do ensino ou da saúde (reciclandose ou orientando-se para outras atividades profissionais). coerente com as aspirações e os fatores acima.

É mais dificil para um jovem inexperiente profissionalmente projetar-se a longo prazo em formação inicial que um jovem adulto em formação continuada. O esforço do jovem para projetar-se ao longo de sua existência, com projetos sucedendo-se ou desenvolvendo-se paralelamente, torna-o mais cético aos efeitos da formação a longo prazo (Dominicé, 2004). As histórias de vida (Pineau, Jobert, 1986; Pineau, 1998) também auxiliam e sempre fizeram parte da perspectiva adotada no meio universitário para a realização do acompanhamento profissional com elaboração do projeto de estudos e profissional. 


\section{A formação de jovens e adultos em contexto francês: investimento político e social}

Uma breve retrospectiva ${ }^{5}$ sobre as medidas em matéria de educação e formação de adultos desde as conferências da Organização das Nações Unidas para a Educação, a Ciência e a Cultura (Unesco) dos anos 90 permite lembrar como se iniciaram as novas perspectivas em formação de adultos (orientação, validação das aquisições, acompanhamento, etc.). Essas medidas orientam, atualmente, as práticas docentes neste campo do conhecimento em vários países da Europa, da América e da África, ${ }^{6}$ dando-se preferência ao contexto francês, que fez parte de nossa experiência profissional nos últimos 20 anos.

Desde 1972, desenvolveram-se políticas europeias sobre a formação de adultos e de educação e, sobretudo, as conferências gerais da Unesco de 1991, 1993 e 1996, presididas por Jacques Delors, propondo uma reflexão sobre a educação para o século 21, em que as questões colocadas foram: Que educação para que sociedade? Como formar ao longo da vida indivíduos que saibam controlar sua vida profissional e pessoal? Foi realizada uma grande consulta junto a representantes de várias atividades e organizações em relação direta e indireta com a educação formal e informal. Esses representantes eram estudantes, professores, pesquisadores governamentais responsáveis, membros de Organização não Governamental (ONG) e grupos de intelectuais.

Em 1995, uma comissão foi nomeada pelo Commissariat Général du Plan (instituição francesa de planejamento governamental) para analisar o tema "o trabalho e o emprego no horizonte de 2015". Dessa comissão, presidida por Jean Boissonnat (1995), antigo membro do Conselho da Política Monetária do Banco da França, resultou um relatório cuja ideia central é a seguinte:

Não é o trabalho que falta. Somos nós que faltamos de clarividência para compreender que ele está mudando radicalmente e que nós não temos suficientemente imaginação para organizá-lo de outra forma. Em vinte anos, segundo o que tivermos feito ou não, a França contará com vários milhões de desempregados ou de franceses que trabalharão de maneira diferente.

Esse relatório apresenta dois objetivos maiores de utilidade para a ação pública e para iniciar um largo debate com a sociedade:

$1^{\circ}$ ) identificar os terrenos onde poderiam intervir de maneira decisiva os atores da vida pública, econômica e social, a fim de dar mais sentido e força à ação pública;

$2^{\circ}$ ) convidar a sociedade francesa para o debate e, depois, para a escolha de um futuro desejável e assumido, nem fatal nem imposto, mobilizando-se em torno de um projeto comum prevendo a exclusão.

De acordo com esse relatório, a sociedade francesa deparou-se com um duplo desafio: responder à persistência do desemprego e fazer com

\footnotetext{
${ }^{5}$ Dados recuperados de nosso trabalho de tese de doutorado em educação, realizada em contexto francês.

${ }^{6}$ Orientamos a pesquisa em nível de Licenciatura e Master, realizada por um público de estudantes africanos, profissionais da área da educação e da saúde, por meio de uma Plataforma Moodle, da Universidade da FrancheComté. Propusemos dois temas para escolha: "Engajamento em formação e escolha profissional" e "Acompanhamento do projeto". No caso do primeiro tema, tivemos uma pesquisa que se iniciou coletivamente, com especificidade trazida pelas problemáticas desenvolvidas individualmente por alguns estudantes.
} 
que a eficacidade econômica não destruisse a coesão social. Vejamos as declarações de René Mabit, o redator-geral da comissão:

[...] a persistência do desemprego, o crescimento das decepções, a evidência dos perigos de explosão ou de implosão que ameaçam a sociedade francesa, se não subsistem rapidamente um alargamento do horizonte temporal de todos os agentes econômicos e atores sociais e um restabelecimento da confiança no futuro, em particular para os jovens, dá-se um caráter de urgência à adoção de uma tal orientação.

Um primeiro relatório formulou o princípio da educação ao longo da vida, com o conceito global de educação - aprender a ser - buscando definir as novas finalidades que assinalam à educação a transformação rápida dos conhecimentos e das sociedades, as exigências de desenvolvimento, as aspirações de indivíduos e os imperativos de compreensão internacional da paz. Publicado em 1976, o documento Recomendações sobre o desenvolvimento e a educação de adultos tornou-se a referência internacional em matéria de educação de adultos.

Os princípios de ação estabelecidos por esse relatório foram os seguintes: o trabalho como direito e fonte de prosperidade, a eficacidade econômica a serviço da dinâmica social, a rentabilidade, a redução das incertezas e desigualdades e o desenvolvimento da responsabilidade civil. Em resumo, é questão de um Estado inteligente, capaz de transformar o quadro regulamentar (novo contrato social) e de adaptar o quadro jurídico ao sistema produtivo.

Mais precisamente, o relatório lembra as recentes mutações no campo do trabalho e do emprego, exigindo várias adaptações, como, entre outras, instrumentos jurídicos relativos às novas relações no trabalho, sua amplitude ética e uma melhor valorização das aquisições profissionais, tudo isso levando em consideração a evolução da população (cuja idade média tende ao envelhecimento - no presente caso, a França), a mobilidade profissional, as responsabilidades e as mudanças nos modos de comando. As propostas em debate referem-se, sobretudo: à ação econômica e política francesa nos planos internacional e europeu; à organização e desenvolvimento das empresas; aos sistemas de valores; à construção de competências; a uma nova gestão dos trabalhos sociais; à nova fundação do emprego no contrato da atividade; e à estimulação do debate social com elaboração de parcerias.

Em novembro de 1995, Barrot, ministro francês do trabalho, encarregou De Virville (1996), secretário-geral do grupo Renault, de formular propostas na base de um eventual processo de refundição do dispositivo de formação profissional, a fim de alcançar sua eficacidade. Esse relatório foi publicado em setembro de 1996, um ano que, segundo a União Europeia, é símbolo da formação ao longo da vida. O objetivo era identificar algumas vias maiores de mudança, a partir das quais poderia preparar-se um movimento no qual a concertação e a negociação coletiva deveriam ficar em primeiro lugar.

O contrato apresentado sobre a formação e o aperfeiçoamento profissional revela que o acordo interprofissional, de 9 de julho de 1970, 
e a lei sobre a organização da formação e o aperfeiçoamento profissional, de 16 de julho de 1971, não ficaram esquecidos, pois o custo total com a formação profissional correspondia (em 1996) a 1,5\% do Produto Interno Bruto (PIB) contra 0,4\% de 20 anos atrás. No entanto, o sistema atual da formação profissional representa de maneira imperfeita o papel de estar a serviço da coesão social e da competitividade econômica.

O relatório compreende, ainda, as seguintes declarações:

[...] a entrada na vida adulta resulta mais seguidamente da impossibilidade de dar continuidade aos estudos que de uma escolha deliberada, de um projeto ativamente conduzido [...]

[...] é então, ao mesmo tempo, em nível econômico e pessoal, que é necessário que a qualificação profissional, concebida como um capital individual, recebida ao longo da vida, torne-se fonte de segurança, permitindo a cada um de livrar-se de um jogo tornado mais complexo.

A proposta apresenta três eixos, que são:

$1^{\circ}$ ) o desenvolvimento de uma formação continuada qualificante pela validação das aquisições (criação de um referencial nacional de competências por categoria e por níveis, controlada pelas regiões para a aplicação) e pelo balanço das competências que constitui um intrumento central de toda prestação de orientação de adultos;

$2^{\circ}$ ) o desenvolvimento de uma formação em alternância como componente da formação inicial. A formação em alternância, enquanto projeto educativo global para a formação profissional inicial, deve ser desenvolvida com estatuto escolar e com contrato de trabalho, no ensino secundário e no ensino superior. Assim, a informação dos jovens sobre as profissões deve ser igualmente melhorada, com as empresas, tanto na escola primária, no ensino médio e no ensino universitário quanto nos quadros socioeducativos;

$3^{\circ}$ ) melhoramento da qualidade das formações e a simplificação dos dispositivos, com dois objetivos visados que consistem em encorajar as questões de qualidade no universo da formação e a desenvolver a cooperação territorial e a formação de proximidade.

Uma análise dos relatórios elaborados pelas comissões encarregadas da educação e da formação profissional dessa época permite demonstrar como foi construída uma concepção social da formação e da educação colocada como um investimento nas inteligências que constitui uma primeira iniciativa para controlar as mudanças sociais (Caspar, 1997) e o contexto do trabalho.

A educação em geral e a formação de adultos caminham ao lado destas politicas, pois tornaram-se um investimento imaterial para as políticas econômicas (Caspar, Afriat, 1988, p. 184). As frequentes mudanças da sociedade, de origem sobretudo econômica, levam ao desenvolvimento 
da complexidade e geram novas regras de funcionamento no sistema. Estudos realizados por outro especialista da formação de adultos na França apresentam esta imaterialização das mudanças no sistema de produção (Dejours, 1988).

A formação torna-se tão somente uma variável estratégica, entre outras tantas, para gerir mudança. Por essa razão, o reconhecimento das aquisições da experiência tornou-se uma via quase que perfeita para dar acesso à qualificação, no contexto francês, originando, entre outras práticas de orientação, a do acompanhamento profissional.

\section{Da noção de orientação à de acompanhamento de jovens e adultos em formação}

No século 20, valorizaram-se tanto as questões de aprendizagem para a educação profissional quanto a prática da orientação de jovens e adultos para uma educação tecnológica a partir da atualização do papel social das instituições de educação e formação.

As implicações da globalização nos aspectos legais da educação profissional e no Plano Nacional de Educação - as propostas do Estado e do empresariado e aquilo que teorias e práticas revelam - contribuem para o aparecimento de novos espaços de formação e novos perfis de profissionais da formação de adultos, com novas tarefas e objetivos.

As pesquisas realizadas sobre a prática da orientação educativa na sociedade ocidental apresentam uma evolução histórica nos últimos 40 anos, demonstrando uma mudança progressiva quanto à representação do trabalho educativo, dos atores e das relações com o meio ambiente (Barbier, 1998).

Impõe-se uma reflexão sobre a noção de acompanhamento do projeto do estudante em qualquer etapa e nível de estudos e, também, sobre todo professor ou formador de adultos empenhado em dar um sentido à disciplina ensinada. Essa reflexão auxilia o estudante adulto ou jovem adulto a dar também um sentido a seus estudos visando à realização de um projeto profissional ao se colocar questões como: Por que se engajar numa formação superior inicial ou continuada? Que sentido esta formação pode ter para seu projeto profissional futuro ou em curso?

As pesquisas de Bourgeois (1996, 2000, 2004, p. 172) se sucedem sobre o assunto, chegando à teoria da instrumentalidade,

[...] onde o engajamento do sujeito numa formação supõe que ele perceba a formação como um meio pertinente a serviço do projeto, de objetivos pessoais (de ordem profissional) específicos.

Bourgeois cita os trabalhos de Dominicé (2004, p. 97) que evidenciam algumas observações sobre o fato de os jovens em início de carreira serem céticos em relação à formação continuada. O trabalho realizado sobre o projeto profissional de jovens adultos torna-se relevante porque, em 
princípio, ele ficaria muito indeterminado para este público. Resultados destas pesquisas apresentam as seguintes afirmações: "vago quanto à definição de objetivos profissionais a longo prazo"; "relação com o emprego ainda indeterminado e em construção, sem real projeto profissional ou com dificuldades para elaborar um"; "desconhecimento do potencial que pode representar a formação continuada e efeitos que ela pode produzir, a saber, um ceticismo quanto à sua capacidade de sustentar um desenvolvimento profissional" (Bourgeois, 2004, p. 173).

As pesquisas belgas e suiças mais recentes ${ }^{7}$ abordam a formação continuada universitária em relação ao percurso profissional e levantam questões relevantes quanto à instrumentalidade da formação continuada universitária. Em especial, os trabalhos de Bourgeois e Dominicé atraíram nossa atenção pela busca do sentido e usos da formação continuada universitária para pilotar o percurso profissional. Concordamos com Bourgeois quando afirma que o paradoxo se encontra no fato de a formação produzir efeitos inesperados para o sujeito, podendo fazer avançar seus objetivos iniciais e também criar novos, de forma a melhor precisar, modificar, transformar ou vê-los ainda como sendo mais ou menos importantes. Parece-nos evidente que, independentemente das condições próprias do sujeito para vivenciar a formação (passivo, pouco passivo, ativo ou muito ativo), o acompanhamento realizado por um profissional da formação poderá participar de uma mudança no seu percurso.

Dando continuidade e aprofundamento às nossas pesquisas sobre a motivação que sustenta um engajamento em formação universitária e a escolha profissional, iniciadas em $1998,{ }^{8}$ chegamos à hipótese de que a presença do profissional do acompanhamento ao lado do sujeito em formação trará maiores oportunidades para que este mude e adote um percurso de formação mais adaptado às suas reais necessidades presentes ou futuras, podendo realizar uma projeção futura com mais facilidade, saindo de uma lógica de instrumentalidade fechada (Bourgeois, 2004) quanto à formação e abrindo-se para outras possibilidades. Segundo o resultado das pesquisas de Fond-Harmant (1996), existe mais de um motivo para o retorno aos estudos, uma diversidade de significações atribuídas a este investimento na formação superior que deixamos aqui como uma pista de pesquisa para aqueles que se interessam pela questão no contexto brasileiro.

Veremos, a seguir, como passamos de uma lógica de orientação à de acompanhamento. A noção de acompanhamento vem sendo construída ao longo desta última década e concerne mais a um público adulto tendo de adaptar-se às novas condições do mundo do trabalho por meio da formação continuada.

A questão da orientação de jovens e adultos evoluiu a partir das pesquisas, como demonstramos anteriormente, mas constatamos uma ocorrência desses termos nos dicionários especializados da educação na França nestes últimos dez anos.

Verificamos nas pesquisas mais recentes em formação de adultos uma preferência pelo termo acompanhamento em substituição ao de orientação. ${ }^{9}$

\footnotetext{
${ }^{7}$ Ver a publicação do resultado completo dessas pesquisas sobre a "formação continuada universitária e o percurso profissional" em Vandamme (2004).

${ }^{8} \mathrm{O}$ mestrado que realizamos com Barbier no Conservatoire National des Arts et Métiers (CNAM) de Paris teve a co-tutela de Bourgeois, da Universidade de Louvain-la-Neuve.

9 Barbier (1998) utilizou a expressão "orientação educativa" em se tratando de adultos em formação continuada.
} 


\footnotetext{
${ }^{10}$ A equipe de pesquisadores da Universidade de Provence, sob a direção de Michel Vial e com a qual temos trabalhado desde 2007, realizou pesquisas na área de formadores da saúde. Por ocasião do Congresso Internacional da Association des Chercheurs et Enseignants en Sciences de l'Èducation-Association pour la Recherche en Éducation et Formation (ACSE-AREF), que comemorou os 40 anos das Ciências da Educação na França em setembro de 2007, apresentamos uma comunicação no Simpósio dirigido por Michel Vial sobre a questão.
}

Em 1998, a primeira noção ainda não existia no Dicionário enciclopédico da educação e da formação; trata-se de uma noção que vendo sendo trabalhada nestes últimos dez anos, no que se refere ao contexto francês. ${ }^{10}$

Nossas pesquisas em dicionários mais recentes nos permitiu encontrar a noção de acompanhamento pedagógico no Dictionnaire de Pédagogie (Morandi, La Borderie, 2006), com 120 noções-chave, 320 entradas e uma classificação de 6 temas, como relacionamos a seguir: sistema educativo; criança e aprendizagens; modelos e métodos; práticas profissionais; mídia e tecnologia; e alguns grandes pedagogos. No interior do quarto tema, relativo às práticas profissionais, encontramos a apresentação da questão do acompanhamento pedagógico, que traduzimos e interpretamos a seguir.

\section{Acompanhamento pedagógico}

A definição da noção de acompanhamento pedagógico presente no Dictionnaire de Pédagogie (Morandi, La Borderie, 2006, p. 162-163) é apresentada como uma modalidade pedagógica regulada, mas que não é dirigida, e faz referência à obra de Pineau (2004) sobre a neodiretividade. O termo acompanhar seria composto por duas palavras de origem latina, cum panis, traduzidas para pão comum, que dariam a ideia de partilha ou de ir com. Acompanhar teria o reconhecimento da dimensão própria do trabalho do estudante e a experiência pessoal de um aprendiz, mas marcaria também a intenção positiva de respeito ao outro, incluindo um processo de troca (relação subjetiva entre pessoas), levando em conta o bom andamento da atividade e das fontes necessárias para ter sucesso (relação objetiva). Outra definição de acompanhamento apresentada está relacionada às formas de individualização, de diferenciação, de consideração das dificuldades do estudante, comprendendo um modo de enquadramento profissionalizado dos percursos individuais, segundo Boutinet (2004).

Essa definição de acompanhamento pedagógico é apresentada como associada aos atos profissionais - os métodos e as técnicas - e às relações humanas, fatos de engajamento e de constante reflexão sobre a incerteza de nossos saberes e de nossos afetos, com referência aos trabalhos de Cifali (2001). O autor havia substituído a expressão de responsabilização (prise en charge) por acompanhamento, questionando o posicionamento do profissional. Este seria colocado ao abrigo de uma violência inscrita habitualmente num encontro, propulsando qualidades como o altruísmo, o respeito, a benevolência, dando importância ao outro, sustentando sem se impor, fazendo obra de generosidade, sem autoridade repressiva, dando-se prioridade às capacidades e projetos do outro, nunca abandonando e entrando em cumplicidade. O outro é reconhecido como capaz de projeto e de iniciativa e não sendo uma vítima em perpétua solicitação de reparação. Isso exige que se creia no sujeito acompanhado como suscetível de atravessar dificuldades presentes e que o acompanhamento seja concebido 
como um momento, permitindo-lhe depois encontrar seus recursos e as solidariedades necessárias para não ficar no mesmo lugar e poder avançar.

Outra citação refere-se a Rogers (1972) participando de uma corrente chamada não diretiva, fazendo da troca e do diálogo as condições do desenvolvimento que é específico daquele que aprende. Nessa concepção, recusa-se a objetivar o estudante e considerá-lo um autor anônimo.

Outro autor referenciado nesta mesma definição da noção de acompanhamento pedagógico é Le Bouëdec (2001), com a função dialogal do acompanhamento que está associada à acolhida e à escuta, num esforço de ajustamento para compreender e transmitir um trabalho de clarificação e de discernimento, de apoio à ação, e capaz de garantir uma função de segurança caminhando ao lado do estudante.

O acompanhamento pedagógico propriamente dito, partindo desta mesma fonte de informação, está relacionado à organização das tarefas. Desenvolve-se sob diferentes aspectos - ajuda individualizada ou em grupo, acompanhamento, tutoramento, entre outros - e tem funções organizadoras (ajustamento de dispositivos), cognitivas (ajustamentos interativos), organizacionais (colocado em situação) e metacognitivas (intervenção mostrando como a tarefa é realizada) relacionadas aos modos pessoais e metodológicos.

A noção de acompanhamento interroga o espaço ocupado pelo professor e seu modo de intervenção. Ser uma pessoa fonte de informação numa dada situação, concebê-la neste sentido e ensinar para não ter que inculcar supõe também organização. O acompanhamento é um espaço a ser construído. Além da associação do companheirismo, designa a ação de ir ao encontro do estudante, de participar de uma produção simultânea e original comum, postulando um efeito particular relacionado a esta associação.

Acompanha-se o encaminhamento, não somente o caminho e o caminhante. É o trabalho em curso o objeto do acompanhamento, procedendo de uma relação integrativa e colaborativa, em oposição ou em complementação do ato magistral.

Citações presentes nessa definição do Dictionnaire de Pédagogie:

O que chamamos de acompanhamento é constituido de um conjunto de comportamentos e de condutas, apoiadas nos saberes, teóricos e práticos, constituindo um tipo de profissionalidade [...] com a finalidade de uma evolução nas relações intersubjetivas. (Ardoino, 2000, p. 4).

[...] trata-se de ajudar a pessoa a melhor gerir a individualização de seu percurso; por outro lado, o acompanhamento apresenta-se como uma des-individualização [...] O paradoxo a arranjar é bem o de uma solidão a afirmar e uma solidaridade a construir. (Boutinet, 2004).

A definição encontrada nesse dicionário não considera outras situações, como a do acompanhamento de profissionais do ensino ou da formação confrontados à aprendizagem de metodologias, tal como a prática do projeto na qual fomos formadas para atuar com jovens universitários. 


\section{Acompanhamento de professores}

Acompanhar professores implica tanto um acompanhamento como sustento ou renovação das práticas pedagógicas diante de reformas que se impõem na educação quanto um aperfeiçoamento de conhecimentos (gestão de processos mentais - método metacognitivo - prática reflexiva) para realizar acompanhamento socioconstrutivista, como os que se apresentam na prática do ensino a distância ou na aplicação da metodologia do projeto (Gélinas, 2004).

Aquele que desejar acompanhar práticas profissionais tem escolhas a fazer ou posições a adotar. É importante que saiba qual o papel que deseja representar, que tipo de situação de mudança está em jogo, que tipo de agente de mudança deseja suscitar. Pode representar o papel de motivador, de empreendedor ou de facilitador, possibilitando que a mudança seja exercida em quatro situações: na transferência de conhecimentos, na reforma, na resolução de problemas e nas transformações adaptativas e evolutivas.

O acompanhante pode ser um agente de implantação ou de mediação, isto é, uma pessoa que queira suscitar a inovação na educação ou na formação, que pode ser de dois tipos: tecnológica ou social. Se nos referimos à introdução de computadores ou da mídia na instituição ou na formação, pode-se falar de inovação tecnológica; em contrapartida, se se trata de mudar os modos de relações entre estudantes e professores ou de criar ajudas ou sustentos, isto pode se aproximar mais da inovação social, ${ }^{11}$ como visado na formação que consiste no acompanhamento da elaboração do projeto pessoal e profissional do estudante, o que vem sendo realizado no ensino superior francês nos últimos 15 anos.

\section{Acompanhamento terapêutico e formação}

Existe uma proposta de formação do acompanhante terapêutico, que se distingue do de ensino, e cuja definição encontrada é a seguinte:

O Acompanhamento Terapêutico é uma atividade que faz falar o sujeito promovendo-lhe algum crescimento psíquico, e acompanhar é, sobretudo, fazer e fazer com o outro, onde este fazer muitas vezes cria um novo segmento na história do sujeito que acompanhamos e o faz aceder muitas vezes pela primeira vez a uma historicidade singular e coletiva, singular porque única em sua experiência, e coletiva, pois se insere na realidade juntamente com a de seus contemporâneos. (Yagiu, 2007, p. 3).

A formação do acompanhante terapêutico proposta é tridimensional, constituída de um trabalho sobre sua própria subjetividade, por meio da experiência pessoal e sua implicação na atividade, com base num quadro teórico aberto às diferentes ciências humanas (Antropologia, Sociologia, Mitologia, Geografia Humana, Urbanismo e outras), com uma prática 
supervisionada pela presença de uma terceira pessoa que lhe mostrará em que momentos poderá ser envolvido e sair da sua profissionalidade por questões pessoais que se atualizam em relação ao sujeito acompanhado.

Para a Psicanálise, toda formação compreende um mecanismo de identificação que não é contido nos livros nem nos cursos universitários habitualmente oferecidos pelas instituições de formação de formadores. Somente nos contextos de formação em que a teoria e a prática estão reunidas, permitindo uma análise desta, como na análise das práticas (Blanchard-Laville, Fablet, 2000), é que se pode falar de formação e não de ensino.

Segundo a definição apresentada por Yagiu (2007, p. 4), a formação: "[...] deve possibilitar a abertura para o questionamento permanente dos efeitos que ela causa, libertando o aprendiz das trincheiras de uma filiação dogmática e inquestionável".

Emprega-se também o termo formação qualificando-a de acompanhante (Robo, 2002). O autor em referência atrai nossa atenção para a análise das práticas de formação como se faz em grupos de formação e de análise que se apresenta como um processo e um dispositivo de formação inscritos numa duração e oferece a vantagem de acompanhar as pessoas que aceitam, voluntariamente, dela participar.

Segundo Robo, esta formação é acompanhante, podendo integrar a formação inicial ou continuada, diferindo de alguns esquemas habituais (estágios, seminários, conferências pedagógicas), mas apresentando uma coerência evidente com as teorias da aprendizagem preconizadas atualmente na educação, que citamos a seguir: centralização nas pessoas engajadas; inserção na alternância e na duração; realizada com os meios existentes; flexibilidade e adaptabilidade organizacional; profissionalização de cada um pelo efeito produzido sobre todos os participantes; produção de saberes da prática favorecendo a teorização desta; e multiplicação dos formadores tendo feito a análise de práticas profissionais.

\section{Acompanhamento e práxis}

A noção de acompanhamento desenvolveu-se no contexto francês, sobretudo pelas pesquisas realizadas junto a profissionais da saúde que necessitavam se especializar no acompanhamento de pessoas socialmente carentes, toxicômanos e jovens em situações precárias que precisavam de uma formação profissional para melhorarem a situação de vida e de todo público jovem ou adulto que carecia de uma orientação para a elaboração de um projeto pessoal ou profissional.

O resultado das pesquisas de Vial (2007) permitiu a elaboração de maneiras de conceber o acompanhamento profissional: forma particular das práticas de sustento; um agir profissional que escapa à concepção cognitivista da ação; uma prática de avaliação; e um tipo de entrevista específico. Os três processos fundamentais em jogo no acompanhamento são: a orientação pela ação, a referenciação e a problematização. 
Michel Vial (2007, p. 15) definiu o acompanhamento como um caso particular de intervenção educativa em que a aquisição do saber erudito não é a finalidade. Acompanhar é ir com e sustentar, isto é, favorecer o potencial da pessoa acompanhada, chamado acompanhado.

Demos preferência a esta definição bastante restrita do acompanhamento, visto que este termo é normalmente utilizado de todas as formas. Parece igualmente interessante, a exemplo de Vial, diferenciar o acompanhamento do ato de guiar ou direcionar ou, ainda, da relação de ajuda.

A pessoa que realiza o acompanhamento, chamada acompanhante, é uma pessoa fonte de conhecimento e de informação que sabe atrair a atenção sobre o que é necessário ao acompanhado para problematizar as situações. Estamos, assim, longe do ato de guiar, em que o guia define o caminho a seguir, embora essas duas práticas sejam de sustentação. Esta atitude que valorizamos permite àquele que é acompanhado ser sustentado para se fortificar e crescer, como sustentamos uma parede para solidificá-la ou, ainda, os corredores de uma mina para permitir ao mineiro cavar mais profundamente.

Ser um acompanhante não é fácil, porque é preciso evitar cair no ato de guiar, o que implica um tipo de relação assimétrica, como a do professor-aluno - o professor é aquele que sabe e o aluno, o que ignora (Vial, 2007, p. 30). Pode-se facilmente cair numa relação de ajuda em que o ajudado depende daquele que o ajuda (p. 45), devendo-lhe reconhecimento e assim saindo do quadro profissional. O acompanhamento significa que é necessário afastar-se de «toda atitude de controle de uma pessoa sobre a outra» (p. 34), o que é particularmente dificil, principalmente quando a escolha da profissão no ensino, no campo social ou na área médica se dá em função da inclinação natural de desejar ajudar o outro.

Para acompanhar, é preciso colocar o acompanhado em situação de autodescoberta, conhecer suas possibilidades, estabelecer relações entre dados considerados isoladamente, permitindo dar sentido às situações vividas no momento devido. Somente com este conjunto de fatores, o acompanhante permitirá ao acompanhado se definir enquanto sujeito, isto é, poder realmente ser ator das mudanças necessárias à realização de seu projeto de vida (estudos, profissão, carreira, etc.).

As funções de professor, diretor de escola, conselheiro pedagógico, psicólogo, psicopedagogo e formador não são simplesmente profissões técnicas, menos ainda mecânicas; são profissões que envolvem fundamentalmente a natureza humana (Cifali, Imbert, 1988), das quais o acompanhamento faz parte em certos momentos.

\section{Concluindo...}

Nas pesquisas desenvolvidas em vários países desde as orientações europeias sobre a formação ao longo da vida, à qual o Brasil também vem aderindo, percebe-se a influência do contexto socioeconômico atual - complexo, evolutivo e incerto - nas políticas de educação. Os indivíduos 
são obrigados a se reciclar, a aprender, para poder antecipar, enfrentar as mudanças e evitar a obsolescência e a exclusão. À medida que os parâmetros habituais desaparecem ou ficam indefinidos, torna-se mais evidente a necessidade de desenvolverem-se ações de acompanhamento, aconselhamento e orientação dos indivíduos em formação.

O desenvolvimento do papel da instituição educacional na sociedade exige mudanças para que esta possa se manter atualizada. É necessário também que se interrogue sobre o papel do professor visando sua maior participação nos projetos societais, nos âmbitos regional, nacional e, mesmo, internacional. Os inúmeros intercâmbios entre as instituições são constatados e integram projetos coletivos e individuais com parcerias de toda natureza (intercâmbio de estudantes e professores, parcerias entre laboratórios de pesquisa, etc.).

Esperamos ter colaborado para uma maior compreensão da ação de acompanhamento na educação e formação de adultos, de forma a impulsioná-la cada vez mais no contexto universitário, para maior inserção e menor exclusão do público jovem e adulto em formação.

\section{Referências bibliográficas}

ARDOINO, Jacques. De l'accompagnement en tant que paradigme. Pratiques de Formation/Analyses, n. 40, p. 5-19, 2000. Disponível em: <http://www.reseaueval.com/content/download/355/1254/file/ ARDOINO\%20Accompagnement\%20paradigme.pdf > .

BARBIER, Jean-Marie. Voies nouvelles de la professionnalisation. Symposium du Réseau de Recherches et Formation (REF), Belgique, set. 1998.

BLANCHARD-LAVILLE, Claudine; FABLET, Dominique. L'analyse des pratiques professionnelles. Paris: L'Harmattan, 2000.

BOURGEOIS, Etienne. L'adulte en formation: regards pluriels.

Bruxellles: De Boeck, 1996.

Le sens de l'engagement en formation. In: BARBIER, Jean-Marie; GALATANU, Olga (Ed.). Formation, sens, signification. Paris: Presses Universitaires de France, 2000. p. 87-106.

Projet et engagement dans la formation professionnelle continue: l'instrumentalité en question - perspective théorique. In: VANDAMME, M. (Ed.). Formation continue universitaire et parcours professionnel. Genève: Université de Genève, 2004. p. 167-188. (Cahiers de la Section des Sciences de L'Éducation, 102). 
BOURGEOIS, Etienne; NIZET, Jean. Regards croisés sur l'expérience de formation. Paris: L’Harmattan, 1999.

BOISSONNAT, Jean. Le travail dans vingt ans: Commissariat général du Plan, rapporteur général René Mabit; rapport de la commission présidée par Jean Boissonnat. Paris: Odile Jacob, La Documentation Francaise, 1995

BOUTINET, Jean-Pierre. Anthropologie du projet. Paris: PUF, 1990.

. Questionnement anthropologique autour de

l'accompagnement: que savons-nous de cet adulte qui part en formation? Savoirs, n. 4, p. 11-49, 2004.

CASPAR, Pierre. L'investissement immatériel. 1997. (Document du CNAM).

CASPAR, Pierre; AFRIAT, Christine. L'investissement intellectuel. Paris: Economica, 1988.

CHAMPY, Philippe et al. Dictionaire encyclopedique de l'éducation et de la formation. 2. ed. Paris: Nathan, 1998.

CIFALI, Mireille. Une altérité en acte. In: CHAPPAZ, Georges. (Dir.). Accompagnement et formation. Marseille: Université de Provence, CDRP de Marseille, 1999. p. 121-160.

. Accompagner: quelles limites? Cahiers Pédagogiques, n. 393, avril 2001.

CIFALI, Mireille; IMBERT, Francis. Freud et la pédagogie. Paris: PUF, 1998. (Coll. Éducation et Formation).

DEJOURS, Christophe. Investir ou s'investir. Éducation Permanente, n. 95, p. 13-20, 1988.

DE VIRVILLE, M. Donner un nouvelle élan à la formation professionnelle: rapport au ministre du Travail et des Affaires sociales. Paris: La Documentation Française, 1996.

DOMINICÉ, Pierre. A quoi sert la formation continue universitaire? Que pensent les professionnels de l'interaction entre formation et emploi? Perspectives culturelles. In: VANDAMME, M. (Ed.). Formation continue universitaire et parcours professionnel. Genève: Université de Genève, 2004. p. 223-243. (Cahiers de la Section des Sciences de L'Éducation, n. 102).

DUBAR, Claude. Trajectoires sociales et formes identitaires: clarifications conceptuelles et méthodologiques. Sociétés Contemporaines, Paris, n. 29, p. 73-83, jan. 1998. 
FOND-HARMANT, Laurence. Approche biographique et retour aux études. Éducation Permanente, Paris, n. 125, p. 7-26, 1995.

Des adultes à l'université: cadre institutionnel et dimensions biographiques. Paris: L'Harmattan, 1996. (Collection Logiques Sociales).

GÉLINAS, Arthur. Les exigences de l'accompagnement dans le renouvellement des pratiques: la perspective du changement en éducation. In: L'HOSTIE, M.; BOUCHER, L.-P. L'accompagnement en éducation: un soutien au renouvellement des pratiques.

Québec: Presses de l'Université du Québec, 2004.

p. 31-45.

HOLLAND, John. L. Making vocational choices: a theory of vocational personalities and work environments. 3. ed. Odessa, FL: Psychological Assessment Resources, 1997.

KADDOURI, Mouktard. Place du projet dans les dynamiques identitaires. Education Permanente, Paris, n. 128, p. 135-152, 1996.

. Vers une typologie des dynamiques identitaires. In: BARBIER, Jean-Marie (Dir.). Action et identité: enjeux pour la recherche en formation. Paris: CNAM, 2001. p. 163-176. (Questions de Recherche en Éducation, 2).

LE BOUËDEC, Guy et al. L'accompangement en éducation et formation: un projet impossible? Paris: L'Harmattan, 2001.

MARTINS, Regina Maria Caruccio. La dynamique motivationnelle qui sous-tend l'engagement en formation et le choix professionnel. Co-tutela da dissertação de Mestrado: Conservatoire National des Arts et Métiers de Paris (Jean-Marie Barbier) e Universidade de Louvain-LaNeuve (Etienne Bourgeois 1999. [Não publicada].

. Formação para a construção de um projeto pessoal e profissional no ensino superior. Revista Prospectiva, Porto Alegre, n. 28, p. 31-37, 2004.

Educando para a construção do projeto pessoal e profissional: uma experiência de ensino na França. Revista Educação, São Leopoldo, v. 11, n. 3, p. 145-155, 2007.

. Dever-avaliar: uma noção e um modelo filosófico para pensar o ato de avaliar. In: OLIVEIRA, Avelino R.; GHIGGI, G. ; OLIVEIRA, Neiva A. Caleidoscópio: temas de educação e filosofia. Pelotas: Ufpel, 2010. p. 79-102. 
MORANDI, Franc; LA BORDERIE, René. Dictionaire de pédagogie. Paris: Nathan, 2006. 272p. (Coll. Éducation en Poche).

PINEAU, Gaston. Accompagnements et histoires de vie. Paris: L'Harmattan, 1998.

. Temporalidades na formação. São Paulo: Triom, 2004.

PINEAU, Gaston; JOBERT, Guy. Les histoires de vie - Tome 1: Utilization pour la formation. Paris: L'Harmattan, 1986.

ROBO, Patrick. Analyse de pratiques professionnelles: un dispositif de formation accompagnante. Vie Pédagogique, n. 122, fev./mar. 2002.

ROGERS, Carl. Liberté pour apprendre. Paris: Dunod, 1972.

VAN ZANTEN, A. (Dir.). Dictionaire de l'éducation. Paris: PUF, 2008.

VIAL, Michel; CAPARROS-MENCACCI, Nicole. L'accompagnement professionnel? Méthode à l'usage des praticiens exerçant une fonction éducative. Bruxelles: De Boeck, 2007. (Collection Pédagogies en Développement).

YAGIU, Hailton. Considerações sobre a formação no acompanhamento terapêutico. Trabalho apresentado no $2^{\circ}$ Congresso Internacional de Acompañamento Terapeutico, realizado em Baía Blanca, Argentina, de 11 a 13 de outubro de 2007. Disponível em: <http://www.psicologia. com.pt/artigos/textos/A0525.pdf>.

Regina Maria Caruccio Martins, doutora em Ciências da Educação pela Universidade de Paris 8, é professora-pesquisadora especializada na orientação do Projeto Pessoal e Profissional nas modalidades presencial e a distancia (EaD). Plataforma Moodle pessoal disponível em: www.e-learningfacile.com/moncours/.

regina.caruccio@yahoo.fr

Recebido em 12 de outubro de 2010

Aprovado em 20 de maio de 2011 